\title{
Time course of large ribosomal subunit assembly in E. coli cells overexpressing a helicase inactive DbpA protein
}

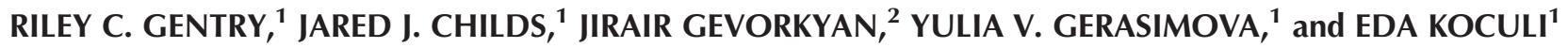 \\ ${ }^{1}$ Department of Chemistry, University of Central Florida, Orlando, Florida 32816, USA \\ ${ }^{2}$ Central Valley Toxicology, Clovis, California 93611, USA
}

\begin{abstract}
DbpA is a DEAD-box RNA helicase implicated in Escherichia coli large ribosomal subunit assembly. Previous studies have shown that when the ATPase and helicase inactive DbpA construct, R331A, is expressed in $E$. coli cells, a large ribosomal subunit intermediate accumulates. The large subunit intermediate migrates as a $45 \mathrm{~S}$ particle in a sucrose gradient. Here, using a number of structural and fluorescent assays, we investigate the ribosome profiles of cells lacking wild-type DbpA and overexpressing the R331A DbpA construct. Our data show that in addition to the $45 \mathrm{~S}$ particle previously described, $27 \mathrm{~S}$ and $35 \mathrm{~S}$ particles are also present in the ribosome profiles of cells overexpressing R331A DbpA. The 27S, 35S, and 45S independently convert to the $50 \mathrm{~S}$ subunit, suggesting that ribosome assembly in the presence of R331A and the absence of wild-type DbpA occurs via multiple pathways.
\end{abstract}

Keywords: DbpA; DEAD-box protein; ribosome maturation factor; RNA helicase; ribosome assembly

\section{INTRODUCTION}

In Escherichia coli (E. coli) cells, the ribosome assembly process involves the interaction of 55 proteins and three RNA molecules and consumes up to $40 \%$ of the cell's energy (Maguire 2009). In order to fulfill the cell's demand for new proteins and to avoid wasting valuable cellular energy, ribosome assembly needs to occur rapidly and accurately. To ensure this, cells use a number of different protein and RNA maturation factors (El Hage et al. 2001; Charollais et al. 2003, 2004; El Hage and Alix 2004; Jain 2008). One class of RNA maturation factors used by the cell during ribosome assembly is DEAD-box RNA helicases (Cordin et al. 2006; Linder 2006; Pyle 2008; Pan and Russell 2010; Shajani et al. 2011; Henn et al. 2012; Putnam and Jankowsky 2013). In vitro, these enzymes use the energy of ATP binding and hydrolysis to unwind short RNA double helices. In vivo, this unwinding activity is believed to facilitate RNA structural rearrangements during the ribosome assembly process (Shajani et al. 2011). E. coli contains five DEAD-box RNA helicases, with four of them (SrmB, DeaD, RhlE, and DbpA) involved in ribosome assembly (Iost and Dreyfus 2006; Jain 2008; Iost et al. 2013).

DbpA (DEAD-box-protein A), which is the focus of this study, is implicated in assembly of the large ribosomal subunit. DbpA binds tightly and specifically to helix 92 of the

Corresponding author: eda.koculi@ucf.edu

Article published online ahead of print. Article and publication date are at http://www.rnajournal.org/cgi/doi/10.1261/rna.055137.115.
23S ribosomal RNA (rRNA), which is located in the peptidyl transferase center of the ribosome (Nicol and Fuller-Pace 1995; Diges and Uhlenbeck 2001; Tsu et al. 2001). The C-terminal domain of DbpA is responsible for its tight and specific binding to helix 92, while the N-terminal RecA-like domains carry out the DbpA protein's ATPase and nonprocessive helicase activity.

It has been previously demonstrated that no changes in growth phenotype are observed when the $d b p A$ gene is deleted from the E. coli chromosome (Baba et al. 2006; Iost and Dreyfus 2006; Elles and Uhlenbeck 2008; Peil et al. 2008). One plausible explanation for the $d b p A$ deletion data is that because correct ribosome assembly is such a crucial process for cell survival, the cell performs this assembly through multiple pathways (Jain 2008; Shajani et al. 2011). In this way, when one of the maturation factors required for ribosome assembly is missing, the assembly can be completed by an alternative pathway and aided by a different maturation factor. In addition to $E$. coli, the $d b p A$ gene is present in many other bacteria (López-Ramírez et al. 2011), suggesting that the DbpA protein could be essential for ribosome assembly under currently undetermined conditions, or when another ribosomal maturation factor is missing.

(C) 2016 Gentry et al. This article is distributed exclusively by the RNA Society for the first 12 months after the full-issue publication date (see http://rnajournal.cshlp.org/site/misc/terms.xhtml). After 12 months, it is available under a Creative Commons License (Attribution-NonCommercial 4.0 International), as described at http://creativecommons.org/licenses/ by-nc/4.0/. 
Interestingly, while no phenotype was observed when the $d b p A$ gene was removed from the E. coli genome, overexpression of ATPase and helicase inactive DbpA, R331A, in the background of endogenous wild-type DbpA produced a cold-sensitive slow-growth phenotype (Elles and Uhlenbeck 2008). More importantly, the ribosome profiles of cells overexpressing R331A DbpA show the accumulation of a $45 \mathrm{~S}$ particle, which is a precursor of the large ribosomal subunit. The accumulation of this particle is believed to be a consequence of the inability of R331A DbpA to facilitate ribosomal RNA structural rearrangement, while preventing wild-type DbpA and other maturation factors, which may perform a similar function to DbpA, access to the large subunit's ribosomal RNA (Elles and Uhlenbeck 2008; Elles et al. 2009).

The protein composition of the $45 \mathrm{~S}$ particle has previously been investigated by mass spectrometry. The $45 \mathrm{~S}$ particle lacks proteins that are added late during ribosome assembly, indicating that the $45 \mathrm{~S}$ particle is a late-stage intermediate on the large subunit assembly pathway. Currently, it is not known whether the $45 \mathrm{~S}$ particle is able to form the 50S large subunit over time in vivo, or whether the $45 \mathrm{~S}$ particle is a dead-end intermediate. If the $45 \mathrm{~S}$ particle is a dead-end intermediate, whether or not the particle is marked for degradation is also unknown. The experiments outlined here investigate the fate of the $45 \mathrm{~S}$ intermediate particle in the large ribosomal subunit assembly pathway when helicase inactive R331A DbpA is present and the wild-type $d b p A$ gene is removed from the E. coli chromosome.

\section{RESULTS}

\section{Determination of RNA composition of separated ribosomal particles}

The ribosome profiles of the cells overexpressing wild-type and R331A DbpA were obtained via sucrose gradients as described in the Materials and Methods section below. Figure $1 \mathrm{~A}$ and $\mathrm{B}$ show ribosomal RNA absorbance at $260 \mathrm{~nm}$ versus the sucrose gradient fractions for cells overexpressing the wild-type DbpA and R331A constructs, respectively. Both profiles have $30 \mathrm{~S}, 45 \mathrm{~S}$, and $50 \mathrm{~S}$ particles present; however, the $45 \mathrm{~S}$ particle is considerably more abundant in the cells overexpressing R331A DbpA. This agrees with previous experimental work (Elles et al. 2009). Interestingly, in cells overexDbpA. pressing R331A DbpA, the 30S peak is broader and contains left and right shoulders. To determine whether the $30 \mathrm{~S}$ shoulders, which migrate as particles of about $27 \mathrm{~S}$ and $35 \mathrm{~S}$ on the sucrose gradient (Fig. 1B), are large ribosome subunit precursors, the RNA composition of the ribosome profiles of cells overexpressing wild-type or R331A DbpA was investigated via a binary deoxyribozyme (biDz) sensor assay. This sensitive fluorescence assay has been used successfully in the past to detect bacterial rRNA both in vitro and in vivo (Gerasimova and Kolpashchikov 2013; Gerasimova et al. 2015).

To perform rRNA content comparison between different fractions of the ribosomal profiles from cells overexpressing wild-type or R331A DbpA, two biDz sensors were usedone targeting E. coli 23S rRNA (biDz-23S) and another specifically recognizing $16 \mathrm{~S}$ rRNA (biDz-16S) (Fig. 1C).
A

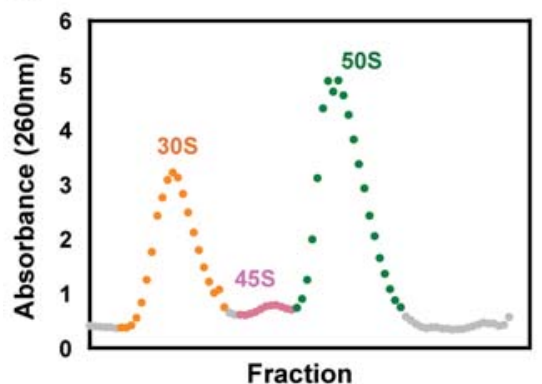

Fraction
B

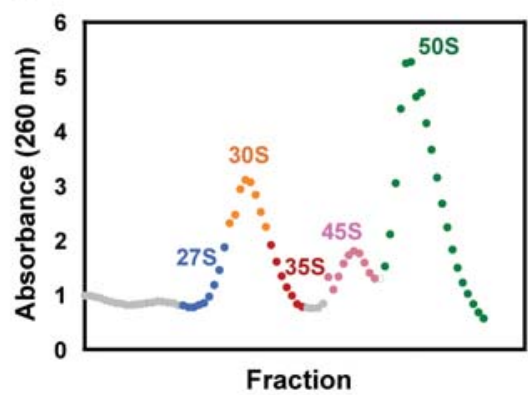

Fraction

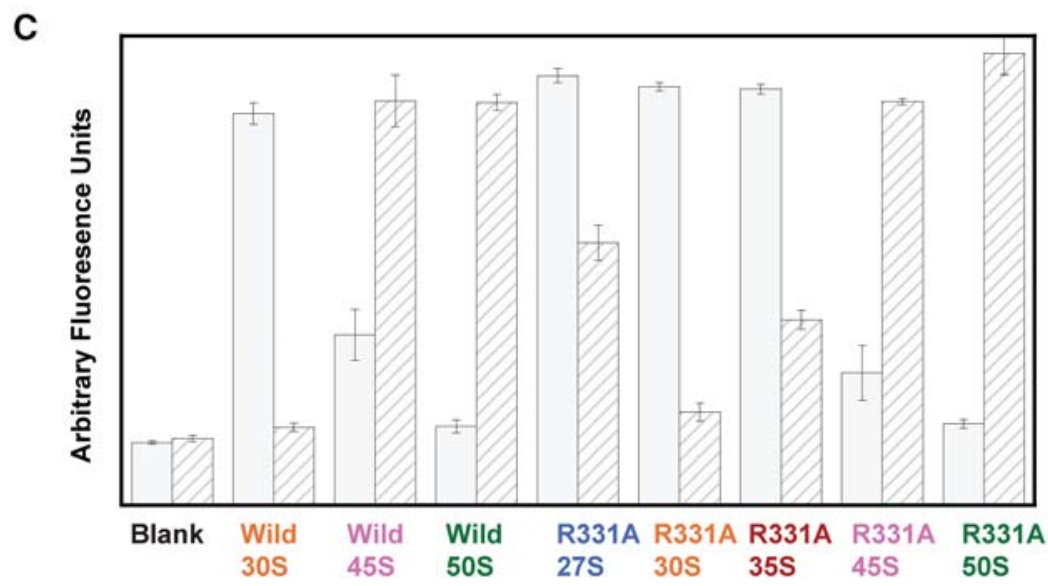

FIGURE 1. Characterization of ribosomal RNA in E. coli cells overexpressing wild-type or R331A DbpA. (A) Ribosome profile of the cells overexpressing wild-type DbpA. (B) Ribosome profile of the cells overexpressing R331A DbpA. The ribosome profiles of the cells overexpressing wild-type or R331A DbpA contained only $1 \mathrm{mM} \mathrm{MgCl}$, which resulted in the ribosomes dissociating into separate subunits. $(C)$ Fluorescent assay with binary deoxyribozyme (biDz) sensors. The fluorescence signals for biDz-16S and biDz-23S are shown as solid gray bars and striped bars, respectively. The amount of RNA used for each particle was normalized to match the fluorescent output of the dominant RNA species (16S rRNA in 27S, 30S, and 35S peak fractions, and $23 \mathrm{~S}$ rRNA in $45 \mathrm{~S}$ and $50 \mathrm{~S}$ fractions) in the particle. Thus, the ratio of $23 \mathrm{~S}: 16 \mathrm{~S}$ rRNA for each particle, which will not change with concentration, should be used to compare the particles. These data show that $23 \mathrm{~S}$ RNA is present both in the right and the left shoulders of the $30 \mathrm{~S}$ peaks on the cells overexpressing R331A DbpA; no 23S RNA was observed migrating with the middle fractions from 30S peak of the cells overexpressing R331A DbpA or the whole $30 \mathrm{~S}$ peak from the cells overexpressing wild-type 
As expected, no difference in the fluorescent response of both biDz-23S and biDz-16S was observed for the fractions corresponding to the $45 \mathrm{~S}$ and $50 \mathrm{~S}$ peaks in both types of cells: $50 \mathrm{~S}$ fractions consisted entirely of $23 \mathrm{~S}$ rRNA, and $45 \mathrm{~S}$ fractions contained $23 \mathrm{~S}$ rRNA and slight amounts of $16 \mathrm{~S}$ rRNA. At the same time, the fractions of $30 \mathrm{~S}$ peaks, and $27 \mathrm{~S}$ and $35 \mathrm{~S}$ shoulders of the ribosome profile from cells overexpressing wild-type or R331A DbpA demonstrated different rRNA composition. The fraction of $30 \mathrm{~S}$ peak (whole $30 \mathrm{~S}$ peak in the cells overexpressing wild-type DbpA and the center peak in the cells overexpressing R331A DbpA) had no $23 \mathrm{~S}$ rRNA present. The $27 \mathrm{~S}$ and $35 \mathrm{~S}$ fractions from cells overexpressing R331A DbpA had a predominantly biDz-16S signal, like those in the presence of $30 \mathrm{~S}$ fractions; however, these fractions also triggered significant fluorescent increase for biDz-23S, indicating that the $27 \mathrm{~S}$ and $35 \mathrm{~S}$ particles are precursors of the $50 \mathrm{~S}$ ribosome subunit. This observation is in agreement with the data from previous primer extension experiments suggesting the presence of large subunit precursors that sediment in a sucrose gradient near the $30 \mathrm{~S}$ particle in the cells overexpressing R331A DbpA (Elles et al. 2009).

In order to further ascertain that in the cells overexpressing R331A DbpA two distinct large subunit precursor particles migrate in a sucrose gradient near the $30 \mathrm{~S}$ small subunit, RNA normalized to the same absorbance at $260 \mathrm{~nm}$ from individual, rather than concentrated, fractions across the entire $30 \mathrm{~S}$ peak were tested with the biDz sensor specific to the $23 \mathrm{~S}$ rRNA (Fig. 2). The biDz sensor experiments show an uneven distribution of $23 \mathrm{~S}$ rRNA across the $30 \mathrm{~S}$ peak, with the left and right shoulder containing a higher amount of $23 \mathrm{~S}$ rRNA. This is consistent with the presence in the cells overexpressing R331A DbpA of two distinct large subunit precur-
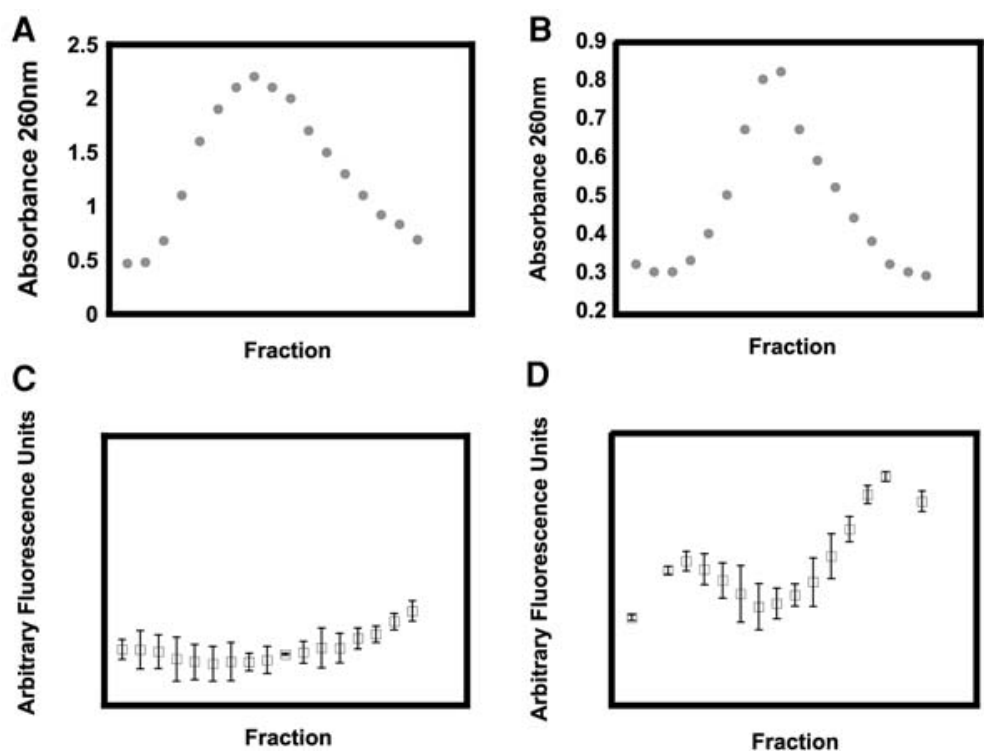

FIGURE 2. $(A, B)$ The UV (absorbance $260 \mathrm{~nm}$ ) profile of the small subunit peak from wild-type $(A)$ and R331A $(B)$ cells. $(C, D)$ The $23 \mathrm{~S}$ rRNA biDz fluorescence profile of the fractions from $A$ and $B$. sors, which migrate in a sucrose gradient as particles of about $27 \mathrm{~S}$ and $35 \mathrm{~S}$. On the other hand, in the cells overexpressing the wild-type DbpA protein, the biDz sensor assay shows an even distribution of the $23 \mathrm{~S}$ rRNA on all the 30S RNA fractions, suggesting that in these cells $27 \mathrm{~S}$ and $35 \mathrm{~S}$ large subunit intermediate particles do not accumulate (Fig. 2).

Having established in the cells overexpressing R331A DbpA the presence of two new and distinct 50S precursors, we proceeded to further investigate their structural and physical properties. First, we investigated the new particles $5^{\prime}$ end $23 \mathrm{~S}$ rRNA processing and compared it to the $5^{\prime}$ end $23 \mathrm{~S}$ rRNA processing observed in large subunit ribosomal particles accumulated in the cells overexpressing R331A or wild-type DbpA. The $5^{\prime}$ end processing of $23 \mathrm{~S}$ rRNA was investigated by ${ }^{32} \mathrm{P}$-labeled primer extension (Fig. 3). The maturation of the $5^{\prime}$ end $23 \mathrm{~S}$ rRNA is poorly understood; however, it is believed that a particle's tertiary RNA structure and protein composition dictate the 23S rRNA maturation extent (Gutgsell and Jain 2010; Shajani et al. 2011). The primer extension reactions clearly show a difference in $23 \mathrm{~S}$ RNA maturation between all four large subunit precursors - 27S, 35S, 45S, and 50S-accumulated in the cells overexpressing R331A DbpA, suggesting that all of these particles have different RNA structure and/or protein compositions as implied from their differences in sedimentation coefficients. The primer extension experiments show that the $45 \mathrm{~S}$ particle accumulated in the cells overexpressing R331A DbpA contains a larger fraction of mature 23S rRNA than the $27 \mathrm{~S}$ particle. On the other hand, the $27 \mathrm{~S}$ particle contains a larger fraction of mature $23 \mathrm{~S}$ rRNA than the $35 \mathrm{~S}$ particle. Thus, it stands to reason that during the ribosome assembly process the pool of $45 \mathrm{~S}$ particles cannot feed into the pool of $27 \mathrm{~S}$ or the $35 \mathrm{~S}$ particles. By the same logic, the pool of $27 \mathrm{~S}$ particle could not feed into the pool of $35 \mathrm{~S}$ particles.

Interestingly, while both the $45 \mathrm{~S}$ particles accumulated in the cells overexpressing R331A DbpA and wild-type DbpA migrate in the sucrose gradient with a similar sedimentation coefficient, they show different extents of maturation. The $45 \mathrm{~S}$ particle accumulated in the cells overexpressing wild-type DbpA contains considerably more fully matured $23 \mathrm{~S}$ rRNA than the $45 \mathrm{~S}$ particle accumulated in the cells overexpressing R331A DbpA. Hence, these two particles are structurally different.

Subsequently we investigated the ability of different particles to stimulate the ATPase activity of the wild-type DbpA protein (Table 1). In order for a particle to stimulate the ATPase activity of DbpA, the DbpA C-terminal RNA-binding domain must have access to hairpin 
A

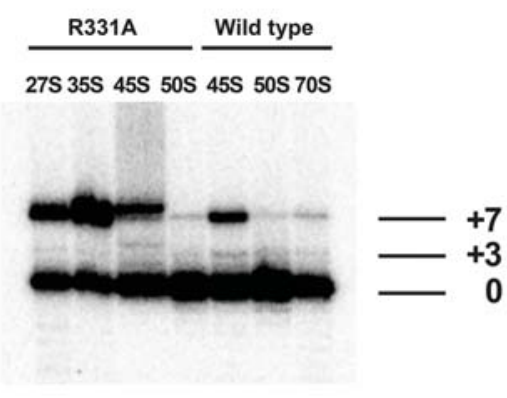

B

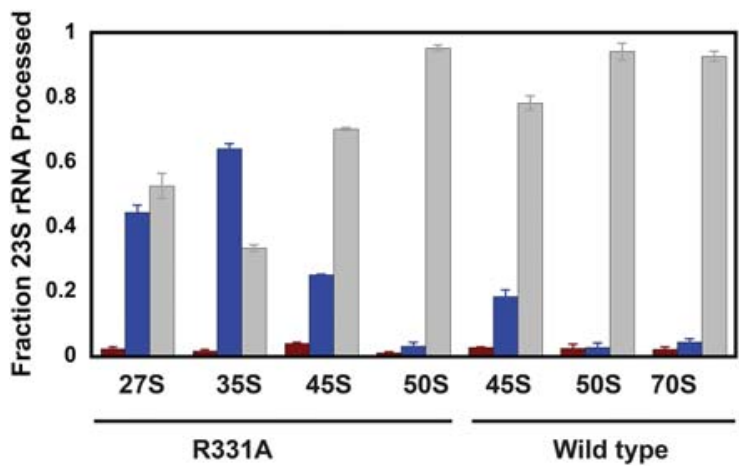

FIGURE 3. (A) A representative gel showing $5^{\prime}$ maturation of the rRNA for the various particles. The mature, +3 , and +7 bands are marked. $(B)$ The fraction of +7 (blue), +3 (red), and maturely (gray) processed $23 \mathrm{~S}$ rRNA for each particle investigated. The fractions for the $+3,+7$ and mature population of each particle represent the means from two independent experiments and the errors are standard deviations from those means. The fractions for the $+3,+7$, and mature population were calculated from the ratio of radioactive counts on a specific band over the sum of counts on the bands representing $+3,+7$, and mature populations.

92 of $23 \mathrm{~S}$ rRNA and the DbpA catalytic core must have access to naked RNA structures. This means that variations in the DbpA protein's ATPase activity could be a consequence of three physical phenomena: (i) Ribosomal proteins could obstruct the DbpA C-terminal RNA binding domain access to hairpin 92, (ii) ribosomal proteins are loaded on the RNA regions that serve as substrates for the DbpA catalytic core, and (iii) the helix and hairpin 92 are not properly formed.

As shown previously, the $50 \mathrm{~S}$ large ribosomal subunit present in the cells overexpressing R331A DbpA or the wild-type DbpA do not stimulate the purified wild-type DbpA protein's ATPase activity (Tsu and Uhlenbeck 1998; Elles et al. 2009). The reason these particles do not stimulate the ATPase activity of the purified wild-type DbpA protein is that helix and hairpin 92 are not solvent accessible in these particles (Ban et al. 2000; Yusupov et al. 2001). Hydroxyl radical footprinting data show that in the $45 \mathrm{~S}$ particle accumulated in the cells overexpressing R331A DbpA, the helix and hairpin 92 are solvent accessible (Arai et al. 2015). Consequently, the experiments presented here and previous studies show that in the cells overexpressing R331A DbpA, the $45 \mathrm{~S}$ particle supports the ATPase activity of the purified wild-type DbpA protein (Elles et al. 2009). On the other hand, we demonstrate here that the $45 \mathrm{~S}$ particle accumulated in the cells expressing wild-type DbpA does not support the ATPase activity of the purified wild-type DbpA protein (Table 1). Thus, the stimulation of the ATPase activity data further suggests that the $45 \mathrm{~S}$ particles accumulating in cells overexpressing wildtype and R331A DbpA have different RNA structures and/ or protein compositions.

The 27S particles accumulating in the cells overexpressing R331A DbpA stimulate the ATPase activity of the wild-type DbpA protein twice as much as the $35 \mathrm{~S}$ particles accumulating in those cells. Hence, the ATPase activation data agree with sucrose gradient migration, biDz fluorescent assay, and primer extension experiments that the $27 \mathrm{~S}$ and $35 \mathrm{~S}$ particles are two distinct intermediate particles with different RNA structures and/or protein compositions.

\section{Kinetics of the intermediates during large subunit assembly}

To investigate if the $27 \mathrm{~S}, 35 \mathrm{~S}$, and $45 \mathrm{~S}$ large subunit intermediate particles form the 50S large subunit over time, we radioactively labeled RNA in vivo for $10 \mathrm{~min}$, stopped the transcription of new RNA by the addition of rifampicin, and followed the change in the radioactive counts of the separated ribosomal particles over time. This pulse labeling technique was used previously to investigate the conversion of a $40 S$ particle, which accumulates in cells lacking DeaD, into the 50 S subunit (Peil et al. 2008). The results of the pulse-labeling experiments are shown in Figure 4, where the RNA absorbance at $260 \mathrm{~nm}$ and the counts per minute (CPM) of radioactively labeled RNA are overlaid.

In cells overexpressing the wild-type DbpA, a small amount of radioactively labeled $45 \mathrm{~S}$ particle is observed, and this particle converts to the 50S large subunit with an observed microscopic rate constant of $0.17 \pm 0.08 \mathrm{~min}^{-1}$ (Fig. 4; Table 3). The observed microscopic rate constant

TABLE 1. ATPase activity of DbpA stimulated by incubation with various large subunit precursor particles

\begin{tabular}{lcc}
\hline DbpA & $\begin{array}{c}\text { Large ribosomal } \\
\text { subunit particle }\end{array}$ & $\begin{array}{c}\text { ATP hydrolyzed per } \\
\text { DbpA }\left(\mathrm{min}^{-1}\right)\end{array}$ \\
\hline Wild type & $45 \mathrm{~S}$ & $4.45 \pm 0.64$ \\
R331A & $50 \mathrm{~S}$ & $3.63 \pm 1.83$ \\
& $27 \mathrm{~S}$ & $37.3 \pm 1.03$ \\
& $35 \mathrm{~S}$ & $19.7 \pm 1.24$ \\
& $45 \mathrm{~S}$ & $42.2 \pm 10.2$ \\
& $50 \mathrm{~S}$ & $3.00 \pm 1.28$ \\
\hline
\end{tabular}

ATP hydrolysis was measured on PEI-Cellulose TLC plates. The rate constant of ATP hydrolysis is the mean of at least two independent experiments, and the errors are standard deviations from the means. 
A
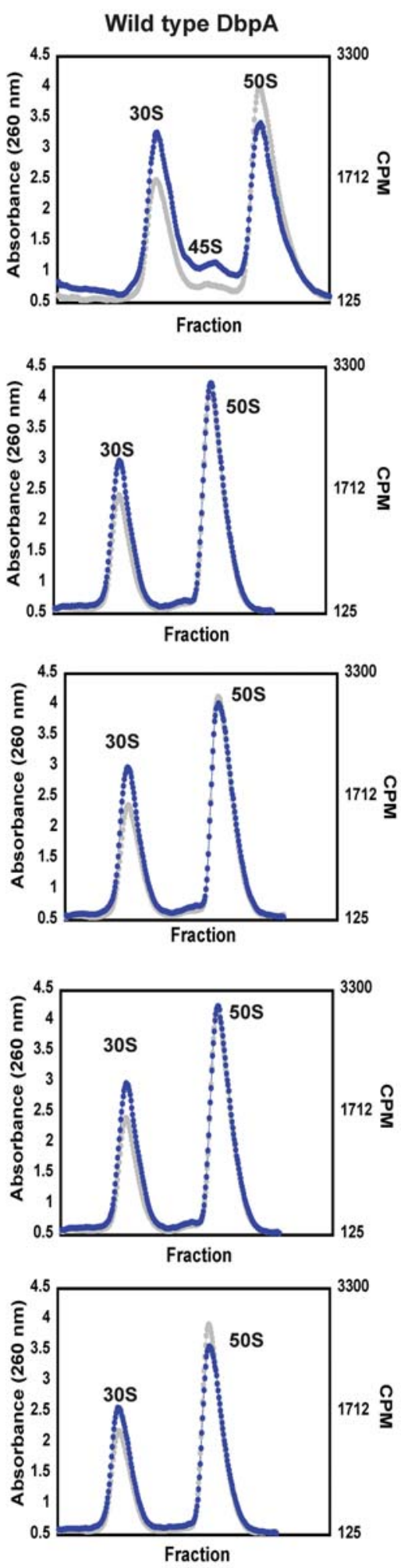

B
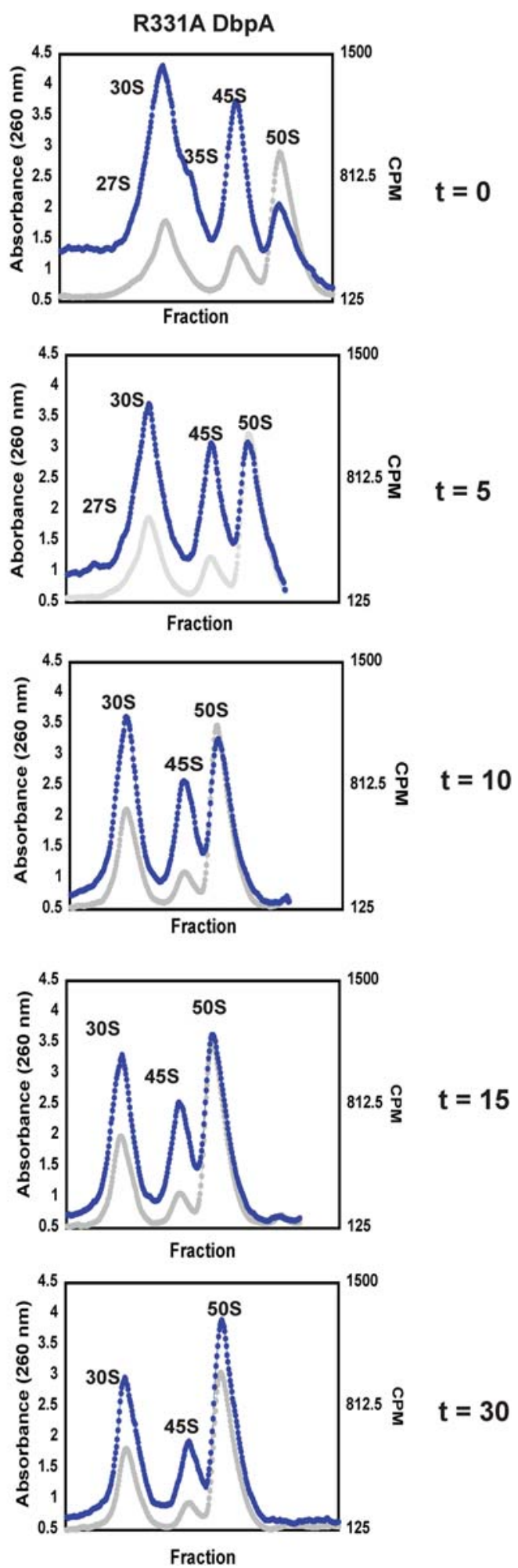

FIGURE 4. Time course of ribosome assembly in cells overexpressing wild-type and R331A DbpA. (A) The time course of ribosome profiles of cells overexpressing wild-type DbpA. (B) Time course of ribosome profiles of cells overexpressing R331A DbpA. The absorbance readings are shown as gray circles and the CPM of ${ }^{3} \mathrm{H}$ labeled RNA as blue circles. The ribosome profiles of both wild-type and R331A DbpA were performed at $0,5,10,15$, and 30 min after addition of rifampicin, which stops new RNA transcription. These data show that over time and with different observed microscopic rate constants (Table 3 ) the $27 \mathrm{~S}, 35 \mathrm{~S}$, and $45 \mathrm{~S}$ particles accumulating in the cells overexpressing R331A DbpA and $45 \mathrm{~S}$ particle accumulating in the cells overexpressing wild-type DbpA form the $50 \mathrm{~S}$ subunit. 
TABLE 2. Relative abundance of ${ }^{3} \mathrm{H}$ labeled ribosomal particles with time

\begin{tabular}{lccccc}
\hline & \multicolumn{5}{c}{ Time after rifampicin addition to cell cultures $^{\mathrm{a}}$} \\
\cline { 2 - 6 } Ribosome particles & $0 \mathrm{~min}$ & $5 \mathrm{~min}$ & $10 \mathrm{~min}$ & $15 \mathrm{~min}$ & $30 \mathrm{~min}$ \\
\hline Wild-type DbpA & & & & & \\
30S & $0.39 \pm 0.02$ & $0.43 \pm 0.06$ & $0.37 \pm 0.02$ & $0.37 \pm 0.02$ & $0.38 \pm 0.01$ \\
45S & $0.13 \pm 0.02$ & $0.10 \pm 0.05$ & $0.07 \pm 0.01$ & $0.06 \pm 0.01$ & $0.07 \pm 0.01$ \\
50S & $0.48 \pm 0.01$ & $0.47 \pm 0.11$ & $0.57 \pm 0.02$ & $0.57 \pm 0.01$ & $0.56 \pm 0.01$ \\
R331A DbpA & & & & & \\
27S & $0.17 \pm 0.01$ & $0.13 \pm 0.01$ & $0.11 \pm 0.01$ & $0.11 \pm 0.01$ & $0.10 \pm 0.01$ \\
30S & $0.22 \pm 0.01$ & $0.19 \pm 0.01$ & $0.19 \pm 0.01$ & $0.19 \pm 0.02$ & $0.18 \pm 0.02$ \\
35S & $0.19 \pm 0.01$ & $0.12 \pm 0.02$ & $0.10 \pm 0.02$ & $0.10 \pm 0.01$ & $0.11 \pm 0.01$ \\
45S & $0.26 \pm 0.01$ & $0.29 \pm 0.03$ & $0.25 \pm 0.01$ & $0.23 \pm 0.01$ & $0.19 \pm 0.02$ \\
50S & $0.16 \pm 0.03$ & $0.27 \pm 0.01$ & $0.35 \pm 0.01$ & $0.37 \pm 0.02$ & $0.42 \pm 0.01$ \\
\hline
\end{tabular}

The fraction of ${ }^{3} \mathrm{H}$ labeled RNA was calculated from the ratio of the counts on the particle over the total counts in all of the ribosomal particles

${ }^{a}$ The numbers are the means from two independent experiments and the errors are the deviations from the means.

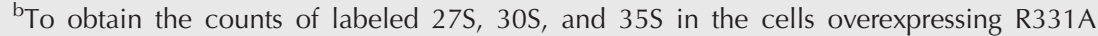
DbpA the ribosome gradient was divided similarly to that used in the fluorescence experiment (Fig. 1C).

was calculated by fitting the data on Table 2 to a single exponential equation. More importantly, no radioactively labeled $27 \mathrm{~S}$ and $35 \mathrm{~S}$ particles were observed in those cells, consistent with the biDz assay (Figs. 1C, 2).

The extent of radioactively labeled $50 \mathrm{~S}$ particles during the labeling phase of our experiment (Fig. 4; Table 2, time, 0 $\mathrm{min}$ ) is considerably smaller in the cells overexpressing R331A DbpA when compared with the cells overexpressing wild-type DbpA. Hence, the overall large subunit assembly pathway is slower in the cells overexpressing R331A DbpA compared to wild-type DbpA (Fig. 4; Table 2). Consequently, at any time fewer active $70 \mathrm{~S}$ ribosomes are present and less protein is synthesized in the R331A DbpA overexpressing cells than in wild-type DbpA overexpressing cells. This explains the observed slow-growth phenotype of cells overexpressing R331A DbpA when compared to the cells overexpressing the wild-type DbpA (doubling time for cells overexpressing the R331A DbpA is $68 \pm 11 \mathrm{~min}$, doubling time for the cells overexpressing wild-type DbpA is $31 \pm 12$ $\min )$.

In the cells overexpressing R331A DbpA, radiolabeled 27S, $35 \mathrm{~S}$, and $45 \mathrm{~S}$ particles are observed in addition to the $30 \mathrm{~S}$ and $50 \mathrm{~S}$ particles (Fig. 4B). The pool of radiolabeled 27S, 35S, and $45 \mathrm{~S}$ particles decreases over time with the concomitant increase of the pool of radiolabeled 50S particles. This combined with the observation that the $27 \mathrm{~S}, 35 \mathrm{~S}$, and $45 \mathrm{~S}$ are not completely processed particles, while the $50 \mathrm{~S}$ particle is (Fig. 3), strongly suggests that the $27 \mathrm{~S}, 35 \mathrm{~S}$, and $45 \mathrm{~S}$ particles are not turnover products of the 50S particle. The observed microscopic rate constants for the rearrangements of the 27S, 35S, and 45S particles are $0.18 \pm 0.03 \mathrm{~min}^{-1}, 0.35 \pm$ $0.11 \mathrm{~min}^{-1}$, and $0.003 \pm 0.001 \mathrm{~min}^{-1}$, respectively (Table 3 ). Consequently, the radiolabeled pool of $27 \mathrm{~S}$ and $35 \mathrm{~S}$ particles completely shifts to the $50 \mathrm{~S}$ particle during the time course of our experiment, while only $20 \%$ of the $45 \mathrm{~S}$ particle pool shifts to the $50 \mathrm{~S}$ particle.

Since only $20 \%$ of the $45 \mathrm{~S}$ intermediate accumulated in the cells overexpressing R331A DbpA rearranges to form the $50 \mathrm{~S}$ subunit, it is possible that this $45 \mathrm{~S}$ particle population consists of two populations, a dead-end population, which never rearranges to form the $50 \mathrm{~S}$ subunit, and a population that rapidly forms the $50 \mathrm{~S}$ subunit. However, the pulse labeling experiments show that the $45 \mathrm{~S}$ particle radiolabeled counts consistently decrease during the entire time course of the experiments, which would be incompatible with the $45 \mathrm{~S}$ particle consisting of a rapidly converting intermediate population and a dead-end intermediate population. If the $45 \mathrm{~S}$ particle accumulated in the cells overexpressing R331A DbpA contained a mixture of a rapid converting and dead-end intermediates, then the radiolabel counts on the $45 \mathrm{~S}$ intermediate would decrease initially fast, and after that initial decrease no change on the $45 \mathrm{~S}$ particle radiolabel counts would occur.

The question remains, do all the intermediate particles present in the cells overexpressing R331A DbpA rearrange to form the 50S subunit via the same pathway; in other words, do these intermediates feed into each other's pools, or do they rearrange to form the $50 \mathrm{~S}$ subunit via independent pathways? Because the $45 \mathrm{~S}$ particle contains more mature $23 \mathrm{~S}$ RNA than the $27 \mathrm{~S}$ and $35 \mathrm{~S}$ particles, the pool of the $45 \mathrm{~S}$ particle cannot feed into the pool of the $27 \mathrm{~S}$ and $35 \mathrm{~S}$ particles. Moreover, the 27S particle contains a larger extent of mature $23 \mathrm{~S}$ RNA than the $35 \mathrm{~S}$ particle; hence, the pool of the $27 \mathrm{~S}$ particle cannot feed into the pool of the $35 \mathrm{~S}$ particle. Consequently, if there were only one pathway for the large

TABLE 3. Kinetics of particle conversion

\begin{tabular}{llc}
\hline DbpA & Particle & Observed microscopic rate constant $\left(\mathrm{min}^{-1}\right)$ \\
\hline R331A & $27 S^{\mathrm{a}}$ & $0.18 \pm 0.03$ \\
& $35 S^{\mathrm{a}}$ & $0.35 \pm 0.11$ \\
& $45 S^{\mathrm{b}}$ & $0.003 \pm 0.001$ \\
Wild type & $45 S^{\mathrm{a}}$ & $0.17 \pm 0.08$ \\
\hline
\end{tabular}

${ }^{\text {a }}$ The observed microscopic rate constants were obtained by fitting the means from Table 2 to the single exponential decay equation $f=f_{(\mathrm{e})}+A e^{-k t}$, where $f_{(\mathrm{e})}$ is the fraction at the end of the time course, and $k$ is the observed microscopic rate constant. The errors are the errors from the fit. The data were fit in Kaleidagraph. ${ }^{\mathrm{b}}$ The R331A 45S particle fit better to a linear equation than exponential decay for the time course of our experiments. The rate of conversion is thus the slope of the linear fit, where the error is the error from the fit. The data were fit in Kaleidagraph. 
subunit ribosome assembly in the cells overexpressing R331A DbpA, the order of particle conversion would be the $35 \mathrm{~S}$ particle rearranging to the $27 \mathrm{~S}$ particle, then the $27 \mathrm{~S}$ particle rearranging to the $45 \mathrm{~S}$ particle and subsequently the $45 \mathrm{~S}$ particle forming the 50S subunit. The $45 \mathrm{~S}$ particle rearranges to form the $50 \mathrm{~S}$ subunit considerably slower than the disappearance of $27 \mathrm{~S}$ and $35 \mathrm{~S}$ labeled counts (Fig. 4; Table 3 ). If the above hypothetical pathway were correct, an increase in the pool of radioactive $45 \mathrm{~S}$ labeled particles would be observed during the time course of our experiments. We do not observe this increase; hence, the $45 \mathrm{~S}$ particle must be formed from a pathway that does not involve either the $27 \mathrm{~S}$ particle or the $35 \mathrm{~S}$ particle, implying that there are at least two different pathways of large subunit ribosome assembly in cells expressing R331A DbpA: one pathway involving the 45S particles, and another pathway involving the $27 \mathrm{~S}$ and $35 \mathrm{~S}$ particles.

Two alternative possibilities exist concerning the fate of the $27 \mathrm{~S}$ and $35 \mathrm{~S}$ particles on large subunit assembly. The first possibility is that the $35 \mathrm{~S}$ particle rearranges to form the $27 \mathrm{~S}$ particle, and subsequently the $27 \mathrm{~S}$ particle forms the $50 \mathrm{~S}$ subunit. Alternatively, the $35 \mathrm{~S}$ and the $27 \mathrm{~S}$ can rearrange to form the $50 \mathrm{~S}$ particle via independent pathways. Since the $35 \mathrm{~S}$ pool of labeled particles depletes faster than the $27 \mathrm{~S}$ pool of labeled particles (Fig. 4; Table 3), if the $35 \mathrm{~S}$ particle pool feeds into the $27 \mathrm{~S}$ particle pool, then the $27 \mathrm{~S}$ particle would accumulate over time. An accumulation of the $27 \mathrm{~S}$ particle is not observed; hence, the $35 \mathrm{~S}$ particle rearranges to form the $50 \mathrm{~S}$ large subunit by a pathway that involves neither the $27 \mathrm{~S}$ nor the $45 \mathrm{~S}$ particles, suggesting that ribosome assembly in the cells expressing R331A DbpA occurs by at least three independent pathways.

Previous work has shown that the 45S particle isolated from cells overexpressing R331A DbpA is unable to form the 50S subunit when incubated with wild-type purified DbpA and ATP (Elles et al. 2009). Moreover, when the lysate made from cells overexpressing R331A DbpA was incubated with excess wild-type DbpA and ATP, the ribosome profiles of the treated lysate were identical to the ribosome profiles of R331A overexpressing cells untreated lysate (Elles et al. 2009). Hence, in vitro the $45 \mathrm{~S}$ particle accumulated in cells overexpressing R331A appears to be a dead-end intermediate. Our experiments show that in vivo, within the time frame of our experiment $\sim 20 \%$ of the $45 \mathrm{~S}$ population converts to the 50 S large subunit (Fig. 4B; Table 2). Thus, in vivo and in vitro pathways of $45 \mathrm{~S}$ particle conversion to the $50 \mathrm{~S}$ large subunit are different. This is consistent with previous results suggesting that ribosome assembly in vitro and in vivo occurs via different pathways (Connolly and Culver 2009; Shajani et al. 2011).

\section{DISCUSSION}

The data presented here show that three large subunit intermediate particles accumulate in cells lacking wild-type DbpA and overexpressing R331A DbpA. The three intermediate particles migrate in a sucrose gradient with different sedimentation coefficients $27 \mathrm{~S}, 35 \mathrm{~S}$, and $45 \mathrm{~S}$, they have different rRNA composition and degrees of $23 \mathrm{~S}$ rRNA maturation, and they stimulate the ATPase activity of wild-type DbpA to different extents. Combined, these data suggest that the three intermediate particles accumulated in the cells overexpressing R331A DbpA are structurally different. The intermediates that migrate in a sucrose gradient as $27 \mathrm{~S}$ and $35 \mathrm{~S}$ particles readily rearrange to form the $50 \mathrm{~S}$ particle, while the $45 \mathrm{~S}$ particle slowly rearranges to form the $50 \mathrm{~S}$ particle (Fig. 4; Table 3). The observation that the radiolabeled counts in the pool of the $45 \mathrm{~S}$ particle shifts to the pool of the $50 \mathrm{~S}$ particle, suggests that the $45 \mathrm{~S}$ particle is not marked for degradation by the cell and is probably not considered toxic (Deutscher 2006). Similar behavior was observed for the $40 S$ particle accumulated in the cells lacking the DEAD-box protein DeaD: This large ribosomal subunit intermediate also rearranges slowly to form the $50 \mathrm{~S}$ particle and is not degraded by cellular machinery (Peil et al. 2008).

The presence of three classes of large subunit intermediate particles, 27S, 35S, and 45S, which independently and with different observed microscopic rates convert to the $50 \mathrm{~S}$ subunit (Fig. 4; Table 3), indicates that in the cells overexpressing R331A DbpA and lacking endogenous DbpA large subunit assembly occurs by at least three different pathways. Multiple pathways of large subunit assembly were also suggested in a previous study investigating the role of DEAD-box proteins RhlE, SrmB, and DeaD on large subunit ribosome assembly (Jain 2008). In this study, the absence of RhlE worsened the slow growth phenotype of the cells lacking the DeaD protein; however, it improved the slow-growth phenotype of the cells lacking the SrmB protein, implying that the presence or lack of a DEAD-box protein in cells may influence the large subunit assembly pathway of choice.

A wealth of previous experimental data has shown that DbpA is a modular protein; the catalytic activity of DbpA is completely housed in its $\mathrm{N}$-terminal domains, while its specific RNA binding activity is housed in its C-terminal domain (Karginov and Uhlenbeck 2004; Karginov et al. 2005). Indeed, changing arginine 331 to alanine in the DbpA protein's catalytic core, while abolishing this construct's ability to hydrolyze ATP and perform unwinding, has no effect on the R331A DbpA protein's affinity for RNA molecules containing hairpin 92 (Elles and Uhlenbeck 2008). Consequently, during in vivo large subunit assembly R331A and wildtype DbpA would be expected to tether to the same RNA intermediate structures and wild-type DbpA should sample the same assembly pathway intermediates as R331A. Therefore, wild-type DbpA, in vivo, may participate in at least three pathways of large subunit assembly.

The precise points on the large subunit assembly pathways at which R331A or wild-type DbpA acts remain unknown. The accumulation of $27 \mathrm{~S}, 35 \mathrm{~S}$, and $45 \mathrm{~S}$ particles in the cells overexpressing R331A DbpA combined with the observation that no phenotype is observed when the $d b p A$ gene is 
removed for the E. coli genome suggests two possibilities. The first possibility is that R331A DbpA acts directly on the intermediate particles. However, because R331A DbpA cannot perform RNA unwinding it cannot facilitate the RNA isomerization steps required for the conversion of $27 \mathrm{~S}$, 35S, and $45 \mathrm{~S}$ particles to the $50 \mathrm{~S}$ particle. Once R331A leaves the intermediate particles, the RNA isomerization steps required for the formation of the 50S subunit could be facilitated by another maturation factor (Elles et al. 2009; Shajani et al. 2011). Due to the fact that ribosome assembly is a very coordinated process (Connolly and Culver 2009; Shajani et al. 2011), the delay in RNA structural rearrangement caused by R331A DbpA binding to the ribosome and its inability to perform unwinding, may promote the formation of alternative incorrect RNA structures or incorrect binding of ribosomal proteins, which could stabilize the intermediate particles. The more stable intermediates would require a longer time to rearrange and form the $50 \mathrm{~S}$ subunit. Consequently, these intermediates accumulate in the cells overexpressing R331A DbpA. The other possibility is that R331A DbpA binds to the precursors of $27 \mathrm{~S}, 35 \mathrm{~S}$, or $45 \mathrm{~S}$ particles and the inability of R331A DbpA to perform its function promotes misassembled intermediate particle formation. Of course it is possible that DbpA binds to certain intermediate particles directly and binds to the precursor of the other intermediate particles.

A ribosomal particle could travel in a sucrose gradient as a particle with a large sedimentation coefficient if it contains a large number of ribosomal proteins, or if it has an incorrectly extended RNA structure (Nierhaus et al. 1973; Dohme and Nierhaus 1976; Charollais et al. 2003). Determination of the $45 \mathrm{~S}$ particle's protein composition showed that this particle is a late stage large subunit ribosomal intermediate (Elles et al. 2009). The R331A DbpA could bind to the $23 \mathrm{~S}$ rRNA before the 45S particle is formed; under this scenario R331A DbpA acts on the early stages of the large subunit ribosome assembly process involving the $45 \mathrm{~S}$ particle. Alternatively, R331A DbpA could directly load onto the 45 S particle; under this scenario R331A DbpA acts on the late stages of the large subunit ribosome assembly process involving the $45 \mathrm{~S}$ particle. Consequently, it is not known when R331A DbpA acts on the large subunit assembly pathway involving the $45 \mathrm{~S}$ particle. Based on their sedimentation coefficients, the $27 \mathrm{~S}$ and $35 \mathrm{~S}$ particles should be earlier large ribosomal subunit intermediate particles. A late large subunit ribosomal particle that contains a large number of ribosomal proteins and a considerable amount of properly formed RNA interactions would not travel as a particle with a small sedimentation coefficient. Therefore, in pathways that involve $27 \mathrm{~S}$ and $35 \mathrm{~S}$ particles, R331A DbpA seems to interact with the 23S rRNA in the earlier stages of large subunit assembly.

Future investigations of the RNA secondary and tertiary structure in the 27S, 35S, and $45 \mathrm{~S}$ particles present in the cells overexpressing R331A DbpA, and the $45 \mathrm{~S}$ particle accumulated in the cells overexpressing the wild-type DbpA, could elucidate the precise RNA isomerization steps that the DbpA protein facilitates and the effect of these structural isomerizations on the large subunit assembly process as a whole.

\section{MATERIALS AND METHODS}

\section{Reagents}

Reagents used for the preparation of cell growth media, including antibiotics, were obtained from Fisher Scientific. DNA oligomers used during the recombineering process and strands of biDz sensors were obtained from Integrated DNA Technologies. The recombineering plasmid pSIM9 was a gift from the Court Laboratory at the National Cancer Institute (Thomason et al. 2007).

\section{Preparation of $E$. coli strains used in this study}

To ensure no interference from the genomic expression of wild-type DbpA, the genomic copy of the $d b p A$ gene was replaced with the kanamycin resistance gene $(k a n R)$ as previously explained (Thomason et al. 2007). The strain used for recombineering was E. coli BLR (DE3) obtained from Invitrogen. The E. coli BLR (DE3) $\triangle d b p A$ : kanR cells were used for all the experiments outlined in this work. These cells were transformed with the pET3a vectors bearing the coding sequence of either wild-type DbpA or R331A DbpA constructs (Elles and Uhlenbeck 2008).

\section{Pulse-labeling experiments}

Pulse chase experiments were carried out by culturing colonies from plates no more than $\sim 16$ h old into $500 \mathrm{~mL}$ of a modified liquid LB media. This media contained $10 \mathrm{~g} / \mathrm{L}$ sodium chloride, $10 \mathrm{~g} / \mathrm{L}$ tryptone, and $1 \mathrm{~g} / \mathrm{L}$ yeast extract, as well as $100 \mu \mathrm{g} / \mathrm{mL}$ carbenicillin and $34 \mu \mathrm{g} / \mathrm{mL}$ chloramphenicol. Cell cultures were grown to an $\mathrm{OD}_{600}$ of 0.2 at $37^{\circ} \mathrm{C}$. After reaching the desired $\mathrm{OD}, 120 \mu \mathrm{Ci}$ of $\left[5,6-{ }^{3} \mathrm{H}\right]$-Uridine was added to the cultures, and allowed an incubation of $10 \mathrm{~min}$. After incubation, rifampicin was added to the culture to reach a final concentration of $500 \mu \mathrm{g} / \mathrm{mL}$. The addition of rifampicin was considered to be time $t=0 \mathrm{~min}$. At time points $t=0,5,10,15$, and $30 \mathrm{~min}, 80 \mathrm{~mL}$ of the culture was collected and poured over ice to rapidly cool the cells. Collection of data at time points longer than $\sim 30$ min was complicated by cell death and degradation of the ribosome particles beginning at $\sim 45$ min after addition of rifampicin. Collected fractions were centrifuged at $6500 \max G$ for $10 \mathrm{~min}$ at $4^{\circ} \mathrm{C}$.

The collected cell pellets were resuspended in $400 \mu \mathrm{L}$ ribosomal lysis buffer (20 mM HEPES-KOH pH 7.5, $30 \mathrm{mM} \mathrm{NH}_{4} \mathrm{Cl}, 1 \mathrm{mM}$ $\mathrm{MgCl}_{2}$, and $4 \mathrm{mM} \mathrm{BME}$ ). The resuspended cells were incubated on ice with lysozyme for $20 \mathrm{~min}$, then flash frozen in liquid nitrogen and thawed in room temperature water. The freeze/thaw cycle was repeated two more times, then $300 \mu \mathrm{L}$ of a detergent buffer $(0.5 \%$ Brij, $0.5 \%$ deoxycholate) with DNase I was added to the raw lysate. The lysate was incubated on ice for $30 \mathrm{~min}$, then placed in a desktop centrifuge at $16,000 \max G$ for $20 \mathrm{~min}$ at $4^{\circ} \mathrm{C}$. The clarified lysate was transferred to new microcentrifuge tubes. The $\mathrm{OD}_{260}$ of the lysate was measured before preparing sucrose gradients. 


\section{Separation of ribosomal particles}

The ribosomal particles were separated by ultracentrifugation in a sucrose gradient as previously described with a few modifications (Elles and Uhlenbeck 2008). Thirty milliliters of $20 \%-40 \%$ sucrose gradients (20 mM HEPES KOH pH 7.5, $150 \mathrm{mM} \mathrm{NH}_{4} \mathrm{Cl}$, $1 \mathrm{mM} \mathrm{MgCl}_{2}$, and $4 \mathrm{mM} \mathrm{BME}$ ) were prepared using a Biocomp Gradient Master. The clarified lysate was layered on top of each gradient, normalized to an amount of $45 \mathrm{OD}_{260}$. Prepared gradients were placed in a Beckman LE-80 ultracentrifuge using a SW-32 rotor and centrifuged at $32 \mathrm{k} \mathrm{RPM}$ at $4^{\circ} \mathrm{C}$ for $16 \mathrm{~h}$. After centrifugation, gradients were fractionated using a Teledyne R1 Fraction Collector and a Brandel SYR-101 Syringe Pump with a 70\% sucrose push from below.

Fractions were collected in Corning UV-transparent 96-well plates. Collected plates were measured for UV absorbance at 260 $\mathrm{nm}$, including pathlength measurements to normalize differences in drop volumes. Finally, the collected fractions were suspended in OptiPhase Supermix liquid scintillation cocktail obtained from PerkinElmer, and tritium CPM was measured using a PerkinElmer MicroBeta liquid scintillation counter. To reduce the effect of instrument noise in the liquid scintillation measurements, the CPM data were passed through an adjacent averaging filter using a 10point window in the data management software, Origin.

\section{Fluorescent assay with $16 \mathrm{~S}$ rRNA- and $23 \mathrm{~S}$ rRNA- specific biDz sensors}

In order to determine the presence of $16 \mathrm{~S}$ and $23 \mathrm{~S}$ rRNA in the ribosome profile fractions, two binary deoxyribozyme (biDz) sensors were used-biDz-16S targeting a fragment of E. coli 16S rRNA (nucleotides 193-240) and biDz-23S targeting a fragment of E. coli $23 \mathrm{~S}$ rRNA (nucleotides 451-500) (Woese et al. 1980; Noller et al. 1981). The sequences of the sensor strands and the fluorogenic reporter have been previously published (Gerasimova and Kolpashchikov 2013; Gerasimova et al. 2015). For the assay, aliquots of the ribosome profile fractions were mixed with strands $\mathrm{a}$ and $\mathrm{b}$ of either of the sensors (15 $\mathrm{nM}$ each), and fluorogenic reporter substrate $(200 \mathrm{nM})$ in a buffer containing $50 \mathrm{mM}$ HEPES ( $\mathrm{pH} 7.4), 50 \mathrm{mM}$ $\mathrm{MgCl}_{2}, 20 \mathrm{mM} \mathrm{KCl}, 120 \mathrm{mM} \mathrm{NaCl}, 0.03 \%$ Triton X-100 and $1 \%$ DMSO and heated at $95^{\circ} \mathrm{C}$ for $3 \mathrm{~min}$. After centrifugation, the samples were incubated at $54^{\circ} \mathrm{C}$ for $1 \mathrm{~h}$ followed by measuring their fluorescence at $517 \mathrm{~nm}$ upon excitation at $485 \mathrm{~nm}$ in a 3-mm cuvette. The amount of the concentrated ribosome profile fractions in the sample was chosen to give the maximum fluorescent signal for the sensor targeting the predominant rRNA in the sample (16s rRNA in $27 \mathrm{~s}, 30 \mathrm{~s}$, and $35 \mathrm{~s}$ peak fractions and $23 \mathrm{~s}$ rRNA in $45 \mathrm{~s}$ and $50 \mathrm{~s}$ peak fractions). As a consequence, the ratio of 23s:16s rRNA for each particle, which is unchanging with concentration, yields information about the rRNA composition in each segment of the gradient. When assaying individual ribosomal profile fractions, the same amounts of RNA based on A260 were used for the assay.

\section{Primer extension assay}

Investigation of the $5^{\prime}$ maturation of the rRNA for the intermediate particles was done using end $\mathrm{P}^{32}$-labeled primer extension. As previously described, a primer corresponding to residues 35-55 of the 23s rRNA was used (Elles et al. 2009). The particles were collected in a $20 \%-40 \%$ linear sucrose gradient, concentrated by ultracentrifugation, and the rRNA was purified by phenol/chloroform extraction. The extension reaction was run using Superscript II reverse transcriptase, purchased from Invitrogen, following the manufacturer's instructions. The reactions were then resolved on an $8 \mathrm{M}$ urea $20 \%$ 19:1 polyacrylamide gel. The gels were dried, exposed to BioRad intensifying screens, and scanned in a BioRad Personal Molecular Imager. The images were quantified using BioRad's QuantityOne basic software.

\section{ATPase assay}

ATPase activity of the particles was investigated using PEI-Cellulose TLC plates as previously described, with the only adaptation being the use of $0.25 \mu \mathrm{Ci} \gamma-\left[{ }^{32} \mathrm{P}\right]$-ATP and a $750 \mathrm{mM}$ LiCl $1 \mathrm{M}$ Acetic Acid running buffer for the PEI-Cellulose TLC plates (Elles et al. 2009). Two microliter aliquots were removed from the reaction every $2 \mathrm{~min}$ and quenched with one microliter $500 \mathrm{mM}$ EDTA over the course of a 20-min reaction, an additional time point at 30 min was taken. The rate of ATP hydrolysis was calculated using the slopes of a linear fit for the time course.

\section{ACKNOWLEDGMENTS}

E.K. thanks O. Uhlenbeck for many helpful discussions concerning this work. This work was supported by National Institutes of Health (5R21CA175625-02 to E.K.) and the University of Central Florida (in-house grant to E.K.).

Received November 3, 2015; accepted April 15, 2016.

\section{REFERENCES}

Arai T, Ishiguro K, Kimura S, Sakaguchi Y, Suzuki T, Suzuki T. 2015. Single methylation of $23 \mathrm{~S}$ rRNA triggers late steps of $50 \mathrm{~S}$ ribosomal subunit assembly. Proc Natl Acad Sci 112: E4707-E4716.

Baba T, Ara T, Hasegawa M, Takai Y, Okumura Y, Baba M, Datsenko KA, Tomita M, Wanner BL, Mori H. 2006. Construction of Escherichia coli K-12 in-frame, single-gene knockout mutants: the Keio collection. Mol Syst Biol 2: 2006.0008.

Ban N, Nissen P, Hansen J, Moore PB, Steitz TA. 2000. The complete atomic structure of the large ribosomal subunit at $2.4 \mathrm{~A}$ resolution. Science 289: 905-920.

Charollais J, Pflieger D, Vinh J, Dreyfus M, Iost I. 2003. The DEAD-box RNA helicase SrmB is involved in the assembly of $50 \mathrm{~S}$ ribosomal subunits in Escherichia coli. Mol Microbiol 48: 1253-1265.

Charollais J, Dreyfus M, Iost I. 2004. CsdA, a cold-shock RNA helicase from Escherichia coli, is involved in the biogenesis of $50 \mathrm{~S}$ ribosomal subunit. Nucleic Acids Res 32: 2751-2759.

Connolly K, Culver G. 2009. Deconstructing ribosome construction. Trends Biochem Sci 34: 256-263.

Cordin O, Banroques J, Tanner NK, Linder P. 2006. The DEAD-box protein family of RNA helicases. Gene 367: 17-37.

Deutscher MP. 2006. Degradation of RNA in bacteria: comparison of mRNA and stable RNA. Nucleic Acids Res 34: 659-666.

Diges CM, Uhlenbeck OC. 2001. Escherichia coli DbpA is an RNA helicase that requires hairpin 92 of 23S rRNA. EMBO J 20: 5503-5512.

Dohme F, Nierhaus KH. 1976. Total reconstitution and assembly of $50 \mathrm{~S}$ subunits from Escherichia coli ribosomes in vitro. J Mol Biol 107: 585-599.

El Hage A, Alix JH. 2004. Authentic precursors to ribosomal subunits accumulate in Escherichia coli in the absence of functional DnaK chaperone. Mol Microbiol 51: 189-201. 
El Hage A, Sbai M, Alix JH. 2001. The chaperonin GroEL and other heat-shock proteins, besides DnaK, participate in ribosome biogenesis in Escherichia coli. Mol Gen Genet 264: 796-808.

Elles LM, Uhlenbeck OC. 2008. Mutation of the arginine finger in the active site of Escherichia coli DbpA abolishes ATPase and helicase activity and confers a dominant slow growth phenotype. Nucleic Acids Res 36: 41-50.

Elles LMS, Sykes MT, Williamson JR, Uhlenbeck OC. 2009. A dominant negative mutant of the E. coli RNA helicase DbpA blocks assembly of the 50 S ribosomal subunit. Nucleic Acids Res 37: 6503-6514.

Gerasimova YV, Kolpashchikov DM. 2013. Folding of 16S rRNA in a signal-producing structure for the detection of bacteria. Angew Chem Int Ed Engl 52: 10586-10588.

Gerasimova YV, Yakovchuk P, Dedkova LM, Hecht SM, Kolpashchikov DM. 2015. Expedited quantification of mutant ribosomal RNA by binary deoxyribozyme (BiDz) sensors. RNA 21: 1834-1843.

Gutgsell NS, Jain C. 2010. Coordinated regulation of 23S rRNA maturation in Escherichia coli. J Bacteriol 192: 1405-1409.

Henn A, Bradley MJ, De La Cruz EM. 2012. ATP utilization and RNA conformational rearrangement by DEAD-box proteins. Annu Rev Biophys 41: 247-267.

Iost I, Dreyfus M. 2006. DEAD-box RNA helicases in Escherichia coli. Nucleic Acids Res 34: 4189-4197.

Iost I, Bizebard T, Dreyfus M. 2013. Functions of DEAD-box proteins in bacteria: current knowledge and pending questions. Biochim Biophys Acta 1829: 866-877.

Jain C. 2008. The E. coli RhlE RNA helicase regulates the function of related RNA helicases during ribosome assembly. RNA 14: 381-389.

Karginov FV, Uhlenbeck OC. 2004. Interaction of Escherichia coli DbpA with $23 \mathrm{~S}$ rRNA in different functional states of the enzyme. Nucleic Acids Res 32: 3028-3032.

Karginov FV, Caruthers JM, Hu Y, McKay DB, Uhlenbeck OC. 2005. YxiN is a modular protein combining a $\operatorname{DEx}(\mathrm{D} / \mathrm{H})$ core and a specific RNA-binding domain. J Biol Chem 280: 35499-35505.

Linder P. 2006. Dead-box proteins: a family affair-active and passive players in RNP-remodeling. Nucleic Acids Res 34: 4168-4180.

López-Ramírez V, Alcaraz LD, Moreno-Hagelsieb G, OlmedoÁlvarez G. 2011. Phylogenetic distribution and evolutionary history of bacterial DEAD-box proteins. J Mol Evol 72: 413-431.
Maguire BA. 2009. Inhibition of bacterial ribosome assembly: a suitable drug target? Microbiol Mol Biol Rev 73: 22-35.

Nicol SM, Fuller-Pace FV. 1995. The "DEAD box" protein DbpA interacts specifically with the peptidyltransferase center in 23S rRNA. Proc Natl Acad Sci 92: 11681-11685.

Nierhaus KH, Bordasch K, Homann HE. 1973. Ribosomal proteins. 43. In vivo assembly of Escherichia coli ribosomal proteins. J Mol Biol 74: 587-597.

Noller HF, Kop J, Wheaton V, Brosius J, Gutell RR, Kopylov AM, Dohme F, Herr W, Stahl DA, Gupta R, et al. 1981. Secondary structure model for 23S ribosomal RNA. Nucleic Acids Res 9: 6167-6189.

Pan C, Russell R. 2010. Roles of DEAD-box proteins in RNA and RNP folding. RNA Biol 7: 667-676.

Peil L, Virumäe K, Remme J. 2008. Ribosome assembly in Escherichia coli strains lacking the RNA helicase DeaD/CsdA or DbpA. FEBS J 275: 3772-3782.

Putnam AA, Jankowsky E. 2013. DEAD-box helicases as integrators of RNA, nucleotide and protein binding. Biochim Biophys Acta 1829: $884-893$.

Pyle AM. 2008. Translocation and unwinding mechanisms of RNA and DNA helicases. Annu Rev Biophys 37: 317-336.

Shajani Z, Sykes MT, Williamson JR. 2011. Assembly of bacterial ribosomes. Annu Rev Biochem 80: 501-526.

Thomason L, Court DL, Bubunenko M, Costantino N, Wilson H, Datta S, Oppenheim A. 2007. Recombineering: genetic engineering in bacteria using homologous recombination. Curr Protoc Mol Biol 78: $1.16 .1-1.16 .24$

Tsu CA, Uhlenbeck OC. 1998. Kinetic analysis of the RNA-dependent adenosinetriphosphatase activity of DbpA, an Escherichia coli DEAD protein specific for $23 \mathrm{~S}$ ribosomal RNA. Biochemistry 37: 16989-16996.

Tsu CA, Kossen K, Uhlenbeck OC. 2001. The Escherichia coli DEAD protein DbpA recognizes a small RNA hairpin in $23 \mathrm{~S}$ rRNA. RNA 7: 702-709.

Woese CR, Magrum LJ, Gupta R, Siegel RB, Stahl DA, Kop J, Crawford N, Brosius J, Gutell R, Hogan JJ, et al. 1980. Secondary structure model for bacterial 16S ribosomal RNA: phylogenetic, enzymatic and chemical evidence. Nucleic Acids Res 8: 2275-2293.

Yusupov MM, Yusupova GZ, Baucom A, Lieberman K, Earnest TN, Cate JH, Noller HF. 2001. Crystal structure of the ribosome at 5.5 A resolution. Science 292: 883-896. 

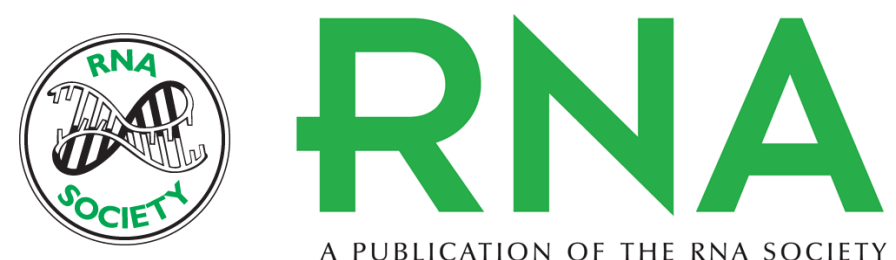

A PUBLICATION OF THE RNA SOCIETY

\section{Time course of large ribosomal subunit assembly in E. coli cells overexpressing a helicase inactive DbpA protein}

Riley C. Gentry, Jared J. Childs, Jirair Gevorkyan, et al.

RNA 2016 22: 1055-1064 originally published online May 18, 2016

Access the most recent version at doi:10.1261/rna.055137.115

\section{References This article cites 39 articles, 11 of which can be accessed free at:} http://rnajournal.cshlp.org/content/22/7/1055.full.html\#ref-list-1

Creative This article is distributed exclusively by the RNA Society for the first 12 months after the Commons full-issue publication date (see http://rnajournal.cshlp.org/site/misc/terms.xhtml). After 12 License months, it is available under a Creative Commons License (Attribution-NonCommercial 4.0 International), as described at http://creativecommons.org/licenses/by-nc/4.0/.

Email Alerting Receive free email alerts when new articles cite this article - sign up in the box at the Service top right corner of the article or click here. 